\title{
The Content of Educational Programs in Technical Universities: Quality of Applying the Modern Professional Standards
}

\author{
Ramil R. Khairutdinov \\ Kazan Federal University, ramilh64@mail.ru
}

Rais S. Safin

Kazan State University of Architecture and Engineering, safin@kgasu.ru

Evgeniy A. Korchagin

Kazan State University of Architecture and Engineering, safin@kgasu.ru

Flera G. Mukhametzyanova

Kazan Federal University, fmukhametzyanova@yahoo.com

\section{Anastasia V. Fakhrutdinova}

Kazan (Volga region) Federal University, avfach@mail.ru

\section{Svetlana R. Nikishina}

Elabuga Institute of Kazan (Volga region) Federal University, radanisovna@mail.ru content of education in Russian technical universities according to the Russian professional standards and the EU Qualification Framework. The content of the professional training of bachelors comprises four educational programs at four technical universities in the Republic of Tatarstan. Over 250 students took part in the survey aimed at assessing their professional skills and knowledge in compliance with professional standards by means of specific tasks designed for this purpose. This allowed us to determine the design of the program and to assess the educational staff awareness of the importance of professional standardization. According to the expert evaluation, the normative content of professional training in the university allows providing higher-level education in case of closer cooperation.

Keywords: professional education, university education, educational standard, technology education, program content, professional competences 


\section{INTRODUCTION}

European Credit Transfer System (ECTS) is an instrument that extends the Bologna Process (Davies, 2018). It was promoted through non-EU, and EU as a transparency tool, and it is aimed to provide equality in skills and qualifications among employees from various countries (Kerwer, 2005). Almost every country has developed its National standards strategy. These strategies refer to the need for high quality specialist education through standards that are reflected in their curricula. Awareness of educational standards on the National level provides experts with instruments for cross-national understanding of the existing problems (El-Bawab \& Effenberger, 2017). The findings in the standardization of the technical education studies reveal that successful involvement in the educational process depends on the national policy, resources availability and the cooperation between employers, standardization comities, educators and the government. Even excellent ideas for professional education standardization do not mean that they will work because of the mechanism of their implementation. That is why it is important to investigate the quality of the existing experiences.

Russian educational standards for higher education are of a framework nature (Abankina, 2018). Thus, the structure of the new Federal State Educational Standards of the Third Generation (FSES $3++$ ) consists of three blocks and practically does not contain a list of the disciplines that should be studied. The FSES specifies that the bachelor's program should ensure the implementation of disciplines (modules) in Philosophy, History (History of Russia, General History), Physical Education, Foreign Language, Fundamentals of Vital Activity Safety and Sports under Block 1 "Disciplines (modules)". The list of other disciplines is established by the educational organization independently proceeding from the results of mastering the educational program, i.e. formed competences. Moreover, only universal and general professional competences are presented in FSES $3++$. Professional competences established by the bachelor's program are formed on the basis of professional standards (PS) and must contain all the obligatory professional competences from the list of an exemplary educational program (EPP) included in the register of exemplary educational programs. One or more professional competences can be determined by the educational organization independently. Thus, it is necessary to take into account the requirements of professional standards in determining the discipline list and the content of training. Therefore, to determine the content of education seems to be a methodological must.

\section{Literature review}

One can note that hrough the globalization, the role of standards in education increases dramatically because it is a part of the sphere of society and human resource development (Stevens, Kurlaende \& Grosz, 2018). Modern professional standards were caused by the fourth industrial revolution that initiated the change from the industrial society to the society based on information and knowledge (Brunsson \& Jacobsson, 2000; Borraz, 2007; Botzem \& Dobusch, 2012). Socio-economic and technological integration depend on advanced technologies in all spheres of our life (SahlinAndersson, 2000; Higgins \& Hallström, 2007). Development of technological standards is also based on standardization of knowledge. Relationships between standards and 
modern economy require educational institutions to pay more attention to standards in professional education (Carnoy, 2017). Professional standards have microeconomic/educational impact on individual companies and employees (Lipset, 2018). As a result, the role of standards in the sphere of professional education has intensified in recent decades (Mc Inerney \& Van Etten, 2007; Brady \& Bates, 2016). For example, standardization in EU formally means flexible, informal coordination. European coordination in higher education standards and their 'voluntary' status are discussed by many authors (Sahlin-Andersson, 2000; Ravinet, 2008; Elken, 2016).

This article outlines the necessity of understanding the didactic basis for the university disciplines. It is acknowledged that the profile of a specialist is determined by the system of skills that he or she owns in practice. In turn, the skills are manifested in the ability to transform the original objects into the given products. The list of the professional skills is reflected in the professional standard, as well as the recent developments around the use of standards that form the basis for the argument in the article. The article then proceeds to discuss discusses the rules, policy-making decisions, and logics involved in standardization. This is followed by a discussion of EU policy modes and governance, as well as the role of standardization in light of the existing conceptualizations and the implications of such developments. While the process of standardization is relevant for educational sector as a whole, the article primarily refers to higher education as a frame of reference. The paper highlights a specific methodology that characterises standards-based governance approach in the Russian context; the way in which this has been exercised at Universities for developing policy capacity in education and higher education, and the consequences and implications of such an approach for global integration in these areas.

Research tasks were as follows:

- harmonization and coherence of the goals of different levels (common to all mankind, state, students and their parents, the needs of organizations and employers' associations) are the basis for achieving the required quality of education;

- participation of students and employers in setting the learning goals, the trajectory, the technology of their achievement, the formation of a personal component of the educational content and practices will contribute to the achievement of the qualification requirements of the future specialist;

- stage-by-stage definition of goals and their achievement is determined by the level of the achievement of the previous stage taking into account the self-development of students.

\section{METHOD}

\section{Research Design}

In the context of the present study, educational programs in the sphere of "Design and technological support of machine-building production" were studied at 4 technical universities in the Republic of Tatarstan (Russian Federation). As it has been already 
mentioned, the new Federal State Educational Standards of the Third Generation (FSES $3++)$ do not contain a list of the studied disciplines. These disciplines are independently established by the university and proceed from the expected results of mastering the educational program, i.e. the formed competences. They are under the responsibility of the Department and the educational staff. It is not clear how to perform them. However, it is necessary to take into account the requirements of the professional standards while developing the learning content at a university.

\section{Procedure}

During the research, all the 44 disciplines' plans were analyzed (4 educational programs at 4 universities). The tasks were designed to determine students' professional skills and knowledge based on professional standards. Students' knowledge was tested by specially designed tasks for determining their professional skills and knowledge according to the professional standards by a number of tasks. The educational program reviewers and the educational quality group of the university examine the tasks that are essential for checking the appropriate competence development.

One task can show the development of several competences at the same time. If a student gets excellent marks (score 5/4 for all tasks - depending on the program 10-12), this means that his/her professional competencies are very well developed. If a student gets good marks (score 5/4/3), this means that his/her professional competences are well developed). If a student gets good/satisfactory marks (score 4/3), this means that his/her professional competencies are satisfactorily developed), if there are low score marks (score 3/2), this means that his/her professional competencies are not developed in an appropriate way. It should be noted that specially designed tasks are tasks that show only professional competences' development. They have nothing to do with the mark that graduates get in their course diploma.

By the same tasks we checked the professional competences of young employees. The research contains both qualitative and quantitative analysis. The qualitative analysis was conducted for more than one year (September 2016 - November 2017). The quantitative analysis was conducted from November 2017 - to March 2018.

\section{Participants}

Students of the technical university who were at the university during the period of the research were invited to take part in it. All 263 students of the $4^{\text {th }}$ year of bachelor level education agreed to take part in our study. The dimensional sampling was used in sampling the participants $-\mathrm{X}$ males $(87 \%)$ and $\mathrm{Y}$ females $(13 \%)$, which reflects the dominant trend in Russian technical universities.

Thirty professors teaching in "Design and technological support of machine-building production" program were interviewed. Twenty-six professors teach the courses held for professional skills development. Four professors failed to take part in the experiment. The professors were asked questions about their understanding of alumni professional activities in accordance with the FSES and professional standards. 
The third group of people involved in the research were 7 enterprises - employers' representatives (among them - the biggest enterprises of Tatarstan - Kazan Helicopter, Kamaz, Niznekamsk Oil-Chemistry plants), they were required to study educational standards of "Design and technological support of machine-building production" bachelor educational program and to give an expert opinion concerning the standards and the level of the alumni (that work at their enterprises, and whether their professional competence development is sufficient). The number of the studied university graduate (2015-2016 year) employees was 77 males.

\section{Research tools}

The courses syllabi and the detailed plans were studied based on the structure of the PS that includes generalized labor functions, labor functions, labor activities, and the required knowledge and skills. For this, 44 programs were studied. The formation of these skills is in the content of the professional training. The skill list was defined as a skill list of the first level. The first level skills are complex goals of the professional training. Implementation of a skill, as a rule, is confirmed by the development of a design or technical document - the product of a specialist's activity.

As long as the course covers all/partly 5-6 level skills, it is understood as excellently designed. If it covers all /partly $4 / 5$, it is understood as well designed. If it covers partly 4-level skills, it is understood as suitably designed, and covering less than 4-level skills it is understood as badly designed. For example, the PS in question represents the following items: «generalized labor function»- development of standard and simple designs of technological equipment and special tools; «labor function» - release of design and technical documentation. Making amendments to the design documentation.

The list of the skills includes both actions representing an independent learning goal for the course, and actions that can be learned only by studying several disciplines. For example, the ability to define the size of a detail and the ability to designate the limit for the shape and location of surfaces can be the goals for several courses of the naturalscience, whether within the disciplinary specialization or minor courses.

\section{FINDINGS}

Goals are understood as a system-forming factor and determine the following principles for constructing the learning content: coordination of social conditions and requirements of the PS, content accordance with the goals of the chosen educational model, content structural unity at the interdisciplinary level, informative and process-activity unity of the learning aspects. From this point the research on the educational programs in the sphere of "Design and technological support of machine-building production" at the selected universities has shown that all of them theoretically cater for the development of necessary competencies and skills of the graduates. For this both the educational staff and the enterprises - employers' representatives noted that it is obligatory to fulfill a significant amount of work with the involvement of appropriately trained performers for the application of the requirements from PS to the content and the goals of studying individual disciplines. Therefore, the educators understand that this work is based on the following prerequisites: the graduates will work in a certain field of their professional 
activity in accordance with FSES after graduation 66\% (34\% of the professors suppose that the students will choose another sphere of work). The professional standard contains a list of functions and labor actions that are entrusted to the employee to $100 \%$.

The list of the functions and labor actions completely determines the skills that are typical for this specialty $75 \%$ (25\% of the professors believe that the list of the competences is too wide). These skills should be a part of the content in the professional training. So interesting results were gained when we studied that only in programs that were designed by professors who are sure that the list of the functions and labor actions completely determines the skills in $90 \%$ students demonstrate very well-developed and $10 \%$ - well-developed professional competencies by the results of the testing tasks. If the professors believe that the list of the competences is too wide - they pay less attention to their development and as a result in their classes students (85\%) demonstrate only satisfactory level of the professional competences developed and (15\%) welldeveloped professional competences. At our research there were no students who demonstrated scoring $3 / 2$. This is due to the fact that students who demonstrate low interest in personal and professional development during their university education are excluded from the educational institution and don't move to the next year of education.

The enterprises-employers' representatives give an expert opinion concerning the standards (they suppose that standards cover the list of the functions and labor actions up to $95 \%$ ) and the level of graduates that work at their enterprises, professional competence development of the alumni employees, who according to the PS study, occupy the following positions: technician-designer; engineer-designer. Their competences were characterized as absolutely sufficient in $70 \%$ and sufficient in $30 \%$. These 77 employees were also asked to solve the same testing tasks that were presented to the students. So the results have shown that absolutely sufficient employees completed tasks in $100 \%$ for $5 / 4$ - very well developed professional skills in all the tests, and sufficient employees at the same time in $100 \%$ for $4 / 3$ - satisfactorily developed professional skills .

All the employers and educators understand that the professional standard is the basis for reflecting the profile of a specialist in the learning process. The didactic basis for the transference of the professional standard into the plans and programs (content) of the student academic activity can be the system of typical tasks for the specialist in the FSES. Such conversion means the transfer of learning goals from the language of skills (functions) to the typical (basic) language of professional activity tasks. The objective expression of the learning content requires an appropriate revision of the necessary knowledge which has never existed by itself. Knowledge is always an element of some activity (or skills). Therefore, the system of knowledge, corresponding to these skills, is being formed simultaneously with the process of forming a system of skills (Mukhametzyanova et al., 2017).

Results show nineteenth programs are of suitable design and allow graduates to achieve the necessary skills. Moreover, these excellent programs were developed by professors who believe that the list of functions and labor activities completely define the skills which are typical and essential for this specialty and vice versa. The research idea was to 
correlate understanding of the importance of professional standards by educators and the results of their students' performance in competences development. Detailed study of each individual competence relies on its integral complicated structure. The deeper the understanding of the professional standards by the professors is, the better the results students demonstrate at tests are.

For example, one takes the skill from the list of skills mentioned above in the PS "Specialist in design of rigging and special tools": performing technical drawings, assembly drawings and details, as well as general drawings in accordance with the USDD standard. This is a skill of the first level (Table 1). A part of the drawing is a design document containing an image of a detail and other information necessary for its manufacture and control (all-Union State Standard 2.108-68). For the development of the drawing of the detail, it is necessary to learn the skills of the second level, specifically.

Table 1

Multi- level structure of drawing of the detail skills of $1^{\text {st }}$ and $2^{\mathrm{d}}$ levels

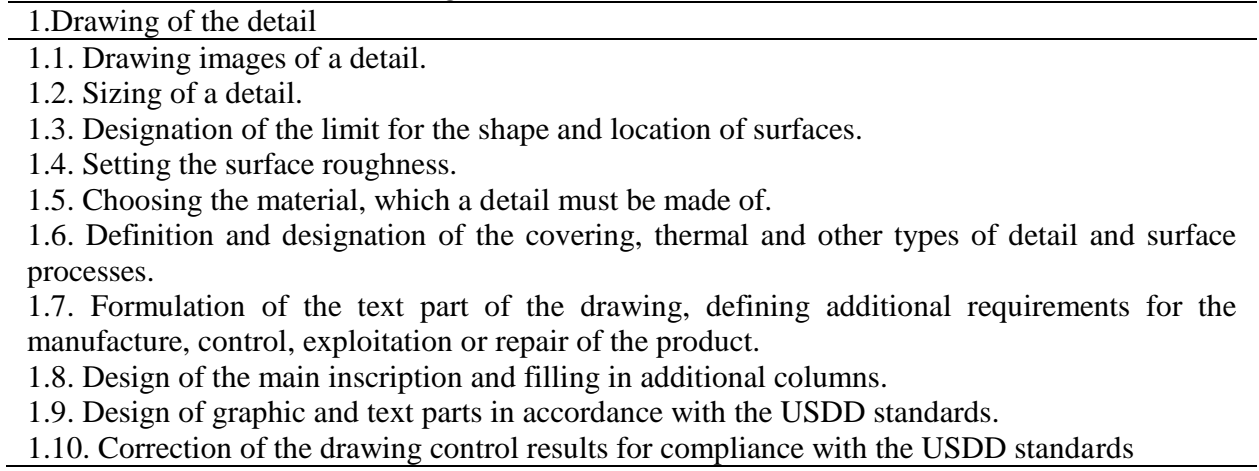

After all, it is possible to define the size correctly when you are able to conduct strength calculations, kinematics calculations of the mechanism, and to define the size in accordance with the requirements for interchangeability, and et cetera. In addition, the size determination influences the technology of the detail manufacturing. It means that it is necessary to learn how to determine the detail size taking into account the manufacturing process (casting, stamping, cutting, welding, and so on). One should be able to set a size that can be checked during the manufacturing process.

It is obvious that the composition of the second level skills is rather complicated. Actions (skills) of the third level can be defined in different ways, for example, by the analysis of the product composition in professional activity. Thus, during the sizing of the detail by the calculation methods (Item 1.2), the following are typical for the third level skills (all-Union State Standard 2.106-68): 
Table 2

Sizing of a detail

1.2.1. Development of a draft or calculation scheme.

1.2.2. Definition of the calculation purpose, which is, setting the task of calculation as its purpose (which is required to determine in the calculation).

1.2.3. Search of the source data for the calculation.

1.2.4. Determination of calculation conditions.

1.2.5. Calculation.

1.2.6. Making a conclusion and writing an explanatory note.

Calculation (item 1.2.5) can also be performed using actions that are still being synthesized while mastering several disciplines.

For example, actions 1.1, 1.8, 1.9 and 1.10 are the immediate goals of a discipline such as engineering graphics. Moreover, these actions are also complex and include the next, the third level, formed directly in the study of this discipline.

After similar analysis of other second level actions, it is possible to get a complete list of skills that must be learned by students in the course of engineering graphics. Such list of skills should be the basis for determining the content of the discipline, types of classes: lectures, practical works, and seminars.

The structure of the listed third level actions is also complex; their content is multidisciplinary, and interdisciplinary. Equally complex is the structure of action $1.5-$ the ability to choose the material, which a detail must be made of (Table 3 ). The ability to choose the material is, in fact, the ability to solve the problem of finding an unknown object that satisfies the statement of the problem, which connects the unknown object (the necessary material) with the given data of this task.

Table 3

Design of the main and additional inscriptions on the detail drawing in the material part 1.9. Design of graphic and text parts in accordance with the USDD standards.

1.9.1. Finding the appropriate state standard for the selected material. This is the ability to work with literature and catalogs in an electronic library. The search for a state standard for materials is the choice of one standard from a huge list. For example, all metals and alloys have about 100 standards, and nonmetallic materials have over 200. It seems that this work should be methodically provided in a proper way. For example, a list of standards for material, which is used in a specific industry, should be compiled. The list should be given to students as a handout.

1.9.2. Definition of the requirements of the standard for the material according to the form of its main inscription on the drawing, i.e. its designation. For example: steel 12 2N3MA FSES 4543-71; press material AG-48 FSES 20437-75; KC50-4 FSES 1216-79; pronate PON 0.8 FSES 481-80, and et cetera. 1.9.3. Designation of the material in column 3 of the main inscription of the drawing (FSES 2.104-68).

The above list of skills, which is necessary for the selection of a material, shows that skills formation helps to develop abstract-logical thinking of students. Indeed, it is impossible to select a material without thinking of operation analysis, synthesis, and comparison. As a result of these operations, students form judgments as the simplest act of thinking, reflecting the connections of objects and their attributes. Several judgments form a new proposition, i.e. there is a transition from private judgments to a more general one, which is a conclusion. 
It is important to mention one disclosure feature of the second and third levels skills for the professional ability to develop a detail drawing: on the basis of the action structure, it is possible to form professional tasks, i.e. tasks for the majority of general professional disciplines. Thus, the development of a detail can be a task for such disciplines as materials science, technical mechanics, interchangeability and standardization of measurements, general technology, and et cetera. The purpose of the assignment must contribute to the formation (even indirectly) of the first-level skill. In order to reduce the time to develop a working drawing, one can give a task to develop a draft of a detail. Thus, it is possible to form directly one more professional activity that is the ability to sketch the details of machines. And the most important skill for a designer will be formed if other goals are achieved (for example, the definition of undulation, surface roughness, and others).

It is possible to select the skills of the fourth and fifth levels from the skills of the third level (Table 4). One can consider, for example, the skill 1.2.6. Making a conclusion and writing an explanatory note. In general, the explanatory note (EN) is a design document containing a description of the device and the operation principles of the developed product, as well as justification of the technical and technical-economic decisions taken during its development (FSES 2.102-68).

In practice of higher educational institutions of the technical profile EN is a distributed document, the product of student learning activities in the performance of coursework, and projects. However, in many cases, the accepted "training" composition of this design document does not contribute much to the formation of professional skills. Meanwhile, the development of EN contributes to the formation of the following skills of the fourth level (FSES 2.106-68).

The content of fourth-level skills includes fifth-level skills that can be independent learning goals for a specific discipline. For example, the description of the working organization with the application of the developed device is a whole complex of fifthorder skills, i.e. the training goals for special disciplines of the mechanical profile connected with the operation, maintenance and repair of equipment.

Table 4

The skills of the fifth level, which are necessary for describing the organization of work with the developed product

1.2.6.6.1. Drawing up the methods of working with the product in different modes and conditions.

1.2.6.6.2. Description of methods of working with the product in the form of both explanation and regulation (if it is necessary).

1.2.6.6.3. Description of the order and methods of transporting the product.

1.2.6.6.4. Description of the order and methods of mounting the product and putting it into operation onsite.

1.2.6.6.5. Description of the order and methods of preservation and storage of the product.

1.2.6.6.6. An estimation of interchangeability of product elements.

1.2.6.6.7. Definition of the serviceability level.

1.2.6.6.8. Evaluation of the maintainability of the product.

1.2.6.6.9. Characteristics of the product resistance against the environmental impact.

1.2.6.6.10. Description of the data characterizing the qualifications and the number of staff.

International Journal of Instruction, January2019 • Vol.12, No.1 
Table 5

The skills of the sixth level appear from the fifth level skills. For example, ability to evaluate the maintainability of a product

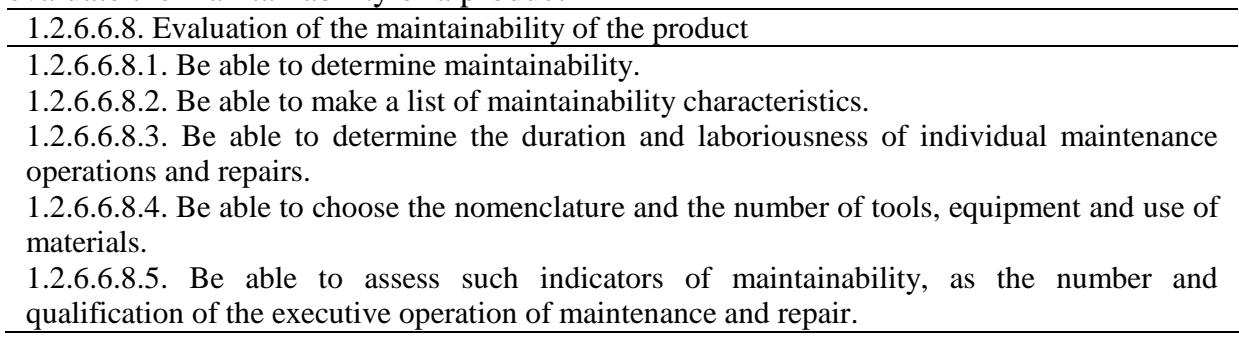

The listed skills of the sixth level (Table 5) are goals of tasks for a specific discipline "Repair and maintenance of equipment".

\section{DISCUSSION}

Modern European integration supposes standards-based approach in almost all spheres of life. The process of standardisation is complicated but challenging. It requires new strategies, new researches, and new mechanisms (Love, Li, Irani and Faniran 2010). The search of them can be traced in all spheres of our social, economic, and political life. Public policy instrumentation and its choice of tools and modes of operation are treated either as a kind of evidence or part of a rationality of methods without any autonomous meaning (Lascoumes \& Le Gales, 2007). New trajectories appeared in education as well. The sphere of higher professional education is limited by general and professional competences, due to the 4th Industrial revolution, so standards-based approach is seen as the way of effective variation skim of knowledge transmission. The formation of professional competences and skills is seen as the content of the educational training. At the same time technical institutions need to improve the quality of instruction if they are eager to be significant players in the world's economic arena (Malechwanzi, 2016)

The experience of Russian technical universities helped to reveal skill list that can be defined as a skill list of the first level. The first level skills are complex goals of professional training. That is why it became possible to consider that the didactic basis for setting the goals and determining the content of the studied disciplines at the university should be revived. It is acknowledged that the profile of a specialist is determined by the system of skills that he demonstrates in practice. In turn, the skills are manifested in the ability to transform original objects into the given products (Korpinen et al., 2004). The list of professional skills is reflected in the professional standard. In many countries governments invest in standard education because it recognized the strategic importance of standards and standardization (ChoiDong-Geun \& De Vries, 2012). Taking a task for improving professional training, it is necessary to have a complete list of the specialist's skills.

In this regard, compiling a list of skills, which are typical for a specialist of this profile, is the first step to the training scheme that is able to ensure the high quality of professional activity. It is important to study the application of this method for designing 
the discipline content on the example of the PS "Specialist in design of rigging and special tools" (PS, 2014) (it makes no difference what kind of PS to take as an example). The selected PS corresponds to the professional activity of graduates who mastered the undergraduate program in the field of study "Design and technological support of machine-building production" (draft FSES, 2017).

It is necessary to emphasize that the set of the professional standards defining fields of the future professional work of graduates is applied to each educational standard. Choosing a professional standard for the development of the training program, it is necessary to take into account that the designed content can correspond to: one professional standard, which has the same program or synonymous name; a part of the professional standard (for example, one of the generalized labor functions described in it); several professional standards, each of which reflects, for example, the activity peculiarities in an industry or describes one of the qualifications, which is learned within the framework of the educational program. The use of professional standards in the field of education is not an easy task, but a feasible one (Lascoumes \& Le Gales, 2007). At the same time, integration of core academics in CTE courses improved students' academic achievement as measured by the standardized assessments (Park et al., 2017). This complexity is determined by different interpretations of qualifications in the field of education and the world of work.

There is a possibility of constant (continuous) updating of the bachelor's professional competences in the new edition of the FSES educational standards, taking into consideration the requirements of employers and professional standards, as their development has not been completed yet. The established mechanisms of interaction will allow the educational and professional community not only to speak the same language, but also conduct an equal dialogue. This circumstance will help to overcome differences in the content of qualifications in education and the world of work. This is possible due to the introduction of an adaptation period for university graduates of a certain period of time, which is necessary for in-depth elaboration of specific requirements for the selected qualification of an employee and the successful pass of a professional (qualification) examination.

\section{CONCLUSION}

The development of the European Qualifications Framework (EQF) requires standardisation of professional education, otherwise graduates of higher education institutions will be able to find a job only in the local market. But even this will be possible if the graduates fit the National standards. At the same time global world requires unified-constricted standards.

To sum up, professors who teach disciplines or a professional block of the educational program should understand the importance of the professional competences development presented in the standards. In this case the results of the graduates' competence development will be high and sufficient for the labour market demands. The completeness of the reduction of goal-skills when each goal of the given level is represented in the form of sub-goals of the next level is in such a way that their totality 
completely determines the original goal-skill represented in the PS. Ordering, arrangement, rational selection and structuring of the educational material is involved in the formation of the necessary skills and knowledge of the students, establishing the optimal sequence of the studied topics and sections of the academic disciplines, and the relationship between them.

The development in the normative content of the fund of evaluation tools for performing intermediate and final certification of students in the areas of training in the university should be carried out by taking into account the requirements of the industry and employers. There is also a possibility of constant (continuous) updating of the bachelor's professional competencies in the new edition of the FSES educational standards, taking into consideration the requirements of employers and professional standards, as their development has not been completed yet. For example, in Russia there is the updated FSES $3++$, which takes into account the requirements of the PS more fully, and promotes the approximation process of these concepts. To this end, professional standards are classified by area of professional activity (register, 2014). It makes primary selection of the PS for the FSES in the training areas easier, as there is a specification of the professional activity with the indication of its scope in FSES $3++$. For example, the spheres of professional activity in FSES $3++$ for the bachelors in the field of "Construction" are the following: education and science; architecture, design, geodesy and design; construction and housing communal services; transport; electric power industry; nuclear industry (FSES $3++, 2017$ ).

The established mechanisms of interaction will allow the educational and professional community not only to speak the same language, but also to conduct an equal dialogue. This circumstance will help to overcome differences in the content of qualifications in education and the world of work. This is possible due to the introduction of an adaptation period for university graduates of a certain period of time, which is necessary for in-depth development of specific requirements for the selected qualification of an employee and the successful pass of a professional (qualification) examination.

\section{REFERENCES}

Abankina, I. V. (2018). The Implementation of the Federal Educational Standards in Preschool Education: The Results of a Survey of Leaders and Teachers. Russian Education \& Society, 60(2), 89-100.

Bologna Process, In M.-H. Chou \& $\AA$. Gornitzka (Eds.), The Europe of Knowledge: Comparing Dynamics of Integration in Higher Education and Research Policies. Cheltenham: Edward Elgar.

Borraz, O. (2007). Governing standards: The rise of standardization processes in France and in the EU. Governance 20: 57-84.

Botzem, S. \& Dobusch, L. (2012). Standardization Cycles: A Process Perspective on the Formation and Diffusion of Transnational Standards. Organization Studies 33: 737762.

Brady, N. \& Bates, A. (2016). The Standards Paradox: How Quality Assurance Regimes 
can Subvert Teaching and Learning in Higher Education. European Educational Research Journal 15: 155-174.

Brunsson, N. \& Jacobsson, B. (2000a). The contemporary expansion of standardization. In N. Brunsson \& B. Jacobsson (Eds.), A world of standards. Oxford: Oxford Univ. Press.

Carnoy, M. (2017). Education, economy and the state. In Cultural and economic reproduction in education (pp. 79-126). Routledge.

Choi, D.-G. \& De V. H. J. (2012). Integrating standardization into engineering education. The case of forerunner Korea https://repub.eur.nl/pub/38422/metis_183224_OA.pdf

Davies, H. (2018). The Recognition of Professional Qualifications: The Part Played by the European University Association in the Alignment of EU Legislation with the Bologna Process. In European Higher Education and the Internal Market (pp. 309335). Palgrave Macmillan, Cham.

Dowson, M., McInerney, D. M. \& van Etten, S. (2007). The state of play in standards and standards reform. In D. M. McInerney, S. van Etten, \& M. Dowson (Eds.), Standards in education. Charlotte, NC: Information Age Publishing.

El-Bawab, T. S., \& Effenberger, F. (2017). Interactive Research-Based Instruction Strategies for Standards Education: Project ISTEE. IEEE Communications Magazine, 55(5), 110-114.

Elken, M. (2016). Standardizing education? The development of the European Qualifications Framework and national qualifications frameworks. University of Oslo Dissertation for the degree of PhD 2016. Oslo

Engström, S. (2018). Differences and Similarities between Female Students and Male Students that Succeed within Higher Technical Education: Profiles Emerge through the Use of Cluster Analysis. International Journal of Technology and Design Education 28(1), 239-261.

Higgins, W. \& Hallström, K. T. (2007). Standardization, Globalization and Rationalities of Government. Organization, 14, 685-704.

Karran, T. (2004). Achieving Bologna Convergence: Is ECTS Failing to Make the Grade? Higher Education in Europe, 29, 411-421.

Kerwer, D. (2005). Rules that many use: Standards and global regulation. Governance, $18,611-632$.

Korpinen, L., Koskiranta, M., Lehtelä, R., Vesapuisto, M., Tepsa, K. \& Puro, H. (2010). The Designing and the Implementation of WWW-course "Electricity, Electronics and Environment". Electronics and Electrical Engineering. - Kaunas: Technologija 6(102), 75-78. 
Lascoumes, P. \& Le Gales, P. (2007). Introduction: Understanding Public Policy through its Instruments - From the Nature of Instruments to the Sociology of Public Policy Instrumentation. Governance 20(1), 1-21.

Lipset, S. M. (2018). Values, education, and entrepreneurship. In Promise Of Development (pp. 39-75). Routledge.

Love, P E. D., Li H., Irani, Z. \& Faniran, O. (2010). Total Quality Management and the Learning Organization: A Dialogue for Change in Construction. Construction Management and Economics, 18(3), 321-331.

Park, T., Pearson, D. \& Richardson, G. B. (2017). Curriculum Integration: Helping Career and Technical Education Students Truly Develop College and Career Readiness. Peabody Journal of Education, 92(2), 192-208.

Ravinet, P. (2008). From Voluntary Participation to Monitored Coordination: Why European Countries Feel Increasingly Bound by Their Commitment to the Bologna Process. European Journal of Education, 43, 353-367.

Sahlin-Andersson, K. (2000). Arenas as standardizers. In N. Brunsson \& B. Jacobsson (Eds.), A world of standards. Oxford: Oxford University Press.

Scholl, M.H. (2008). (Some) Formal foundations of modelling dynamics. http://www.inf.uni-konstanz.de/fileadmin/dbis/im08/4-Dynamik-B.pdf.

Shuaibu, H., Jogana, M. A. \& Mukhtar, N. (2018). Integrating Entrepreneurship and Technical Education as a Panacea for Graduates Unemployment in Nigeria. British Journal of Education, 6(3), 57-71.

Stevens, A. H., Kurlaender, M. \& Grosz, M. (2018). Career technical education and labor market outcomes: Evidence from California community colleges. Journal of Human Resources 1015-7449R2.

Vesapuisto, M., Vekara, T., Korpinen, L., Koskiranta, M. \& Lehtelä, R. (2010). The Students' Feedback on Kaunas. Technologija 6(102): 99-102.

Wanjala, G. \& Malechwanzi, J.M. (2016). Improving the Quality of Technical Education Through International Standardization: The Case of Coast Institute of Technology, Kenya. In: Amzat I., Yusuf B. (eds) Fast forwarding Higher Education Institutions for Global Challenges. Springer, Singapore. 